Ljubljana

\title{
KRITISCHE SICHT DER LITERATUR ÜBER DIE (SÜDSLAWISCHE) ENTSPRECHUNG DER GRUPPE *tl/dl UNTER SPEZIELLER BERÜCKSICHTIGUNG DES RUMÄNISCHEN mocirlă
}

Das Problem der Entsprechung der urslawischen Verbindung *tl/dl in den süslawischen Sprachen war teilweise Gegenstand von kontroversen Interpretationen. Noch besonders strittig war die Interpretation des zweifachen Nachweises in den Freisinger Denkmälern. So stellt z.B. Issatschenko 1943 in seiner deutschen Zusammenfassung folgendes fest (S. 85): "Neben $d l$ in modliti, modlim, vzedli II 59, 36, 62 haben wir bereits assimiliertes $l$ in crilatcem I 4. /.../ Ramovš vertritt nun, ebenso wie Grafenauer, die These, Freis. I sei in Kärnten entstanden /.../. Aber gerade die Kärntner slov. Dialekte haben altes $d l$ bewahrt, vgl. gailtalerisch kriduno. Warum haben wir dann nicht auch *kridlatcem ? Für uns ist hier wichtig, dass Freis. II eine andere Lautung hat, als die beiden Beichten, die, nach Ramovš, den 'jüngeren' Sprachstand aufweisen." 1

In der Weiterführung werden nur einige Interpretationen herangezogen, besonders solche, welche die konkrete Problematik im Zusammenhang mit der Lage im Slowenischen und in den Freisinger Denkmälern betreffen. Es scheinen in dieser Hinsicht folgende Tatsachen bzw. Fragen wesentlich: 1) dass die Verbindung $t l / d l \mathrm{im}$ Westslawischen erhalten ist; 2) dass sie im Südslawischen zu $l$ assimiliert worden ist mit Ausnahme der slowenisch-dialektischen Vertretung. Dabei müsste man überprüfen, ob es Indizien gibt für die Annahme, dass die Verbindung $t l / d l$ auch breiter auf südslawischem Gebiet, insbesondere im Kroatisch(dialektisch)en erhalten blieb; 3) ob ein genetischer Zusammenhang zwischen der Erhaltung der Verbindung $t / / d l$ im slowenisch-dialektischen Vorkommen und im Westslawischen besteht; 4) wie verbreitet

1 Vgl. dazu Bajec 1949, S. 161: "Adh. ima ohranjeno skupino-dl-: modlim, vzedli, v spovednih formulah pa imamo crilatce. Resda je še danes v ziljskem narečju skupina ohranjena, toda potem je nerazložljiv njen izpad v crilatcem. Po Ramovšu za tako zgodnjo dobo ni misliti na dialektično diferenciacijo.- Predvsem je za Isačenkovo daljnosežno sklepanje premalo primerov. Naj opozorim na nekatere možnosti, ki bi vsaka od njih utegnila spodbiti njegovo argumentacijo. Že 1. 1060-70 je pisano Dulieb (pri Spittalu ob Dravi). Prvotni skupini -tl-, $-d l$ - sta tudi $\mathrm{v}$ današnji ziljščini prešli $\mathrm{v}-l$ - pri težko izgovorljivi kombinaciji konzonantov: gr̀mo. Po disimilaciji nahajamo istotam kadíwo. Ravno oblika modliti kaže še danes veliko razširjenost izven Koroške (Slovenj Gradec, Pohorje, Kozjak, Savinjska dolina, Konjice: prim. Ramovš, H. G. II §§ 105-108!). Že Meillet, Études 316, je mislil na disimilacijo v crilatcem."

Die Entwicklung der Verbindung * $t l / d l$ behandeln alle vergleichenden slawischen Grammatiken. Vgl. u. a. z.B. Miklosich 1879, S. 412,343 f.; Vondrák 1924, S.466, 396; Vaillant 1950, S. 88 f. 
die Beibehaltung der Gruppe $t l / d l$ ursprünglich sein sollte; 5) man muss die Tatsache beachten, dass die Verbindung $t / / d l$ in dem Altkirchenslawischen nicht vorkommt.

Diese Fragen sind für die Bestimmung der Entstehungsgeschichte bzw. des Ursprungs der Freisinger Denkmäler besonders wichtig, da die Beibehaltung der Gruppe $t l / d l$ einen Archaismus darstellt und dadurch eine geringere Beweiskraft hat als es einer Innovation zukomme. Dennoch ist die Beweiskraft dieses Arguments (in Verbindung mit den anderen) verhältnismässig gross, wenn es sich, wie es scheint, um einen isolierten Fall der Erhaltung auf südslawischem Gebiet handelt.

Ramovš hat die zitierte Problematik an mehreren Stellen erörtert, so Ramovš 1924 und Ramovš 1936. Man vergleiche Ramovš 1924, S. 191 f., wo er eingehend die Entwicklung der Verbindung $t l / d l$ in den slawischen Sprachen behandelt. So sagt er (S. 193) folgendes: "Ugotoviti moremo, da je najmanj vsa severna slovenščina na svojem novem ozemlju v Alpah še dolgo ohranila $t l$ - $d l$. Starejši zapiski krajevnih imen po Alpah kažejo še $d l$, ki ga najdemo deloma še danes v ondotnih nemških imenih, prevzetih od alpskih Slovanov." Auf S. 195 führt er folgendes an (was für eine ev. direkte Verbindung mit rum. mocirlă von Bedeutung ist): "Prvotno močidlo "Lache, Morast "imamo ne le v ziljskem Močidlo, nem. Matschidel (na severu Blač), marveč tudi na Štajerskem: Muntschiedel 1.1495 (poljsko ime blizu Frohnleitena) in Ötscherl $(r l<d l)$, Oschelling $<*$ močidlbniks $(l l<r l<d l$ : začetni $m$ - so smatrali za element predloga: am-očərl 'am Motscherl'), za kar beremo v starejši dobi Muotschil, Mosnich, Mötscheling in pod. /.../. Iz teh imen moremo razbrati, da so nemški kolonisti, ki so od VIII. stol. dalje prihajali v stike $\mathrm{z}$ alpskim slovanskim svetom, našli $\mathrm{v}$ jeziku alpskih Slovanov še skupino $d l$ : asimilacija $t l-d l>l$ se je vršila torej kasneje, po narečjih različno, tu prej tam pozneje."2 Im Zusammenhang mit der Vertretung in den Freisinger Denkmälern vgl. ibid., S. $197^{3}$, und hinsichtlich der zeitlichen bzw. geographischen Verbreitung der erhaltenen Verbindung $t l$ - $d l$ vgl. noch Ramovš 1924 an mehreren Stellen. ${ }^{4} \mathrm{Zu}$ der evtl. Zusammengehörigkeit dieses Phänomens mit der westsla-

2 Vgl. weiter ibid., S. 195 f.: "Po nekod pa se je skupina $t l-d l$ ohranila celo do danes; tako imamo $v$ ziljskem narečju /.../. A tudi ostala severna slovenska narečja kažejo po nekaterih redkih ostankih na to, da so imela nekdaj še neasimilirano $t l$-dl. Tu je predvsem omeniti zelo veliko razširjenost oblike modliti /.../; mòdlit govoré v okolici Slovenjga Gradca, na Pohorju, v kozjaškem narečju (levi breg Drave nad Marenbergom), v Savinjski dolini, v okolici Konjic", und $196 \mathrm{f} .:$ ".../ ne zdi se mi presmelo, ako trdim, da so tudi koroška narečja prej, predno je ta izposojenka izpodrinila domačinko, rabila obliko modliti; to mnenje podpiram $\mathrm{z}$ izkazom nekdanjega rož. modliti v Meg. ${ }^{2}$ : Modlit A $5 \mathrm{~b}$, modlitva S 4b, modlitui $\mathrm{P} 6 \mathrm{~b} . "$

3 "Končno omenimo, da piše drugi brižinski spomenik modliti II. 59, modlim II. 36, vzedli II. 62, v prvem imamo pa krilatcem I. 4; to si moremo razlagati kakor tere poleg -že, me poleg moje, grech poleg grechou, -go poleg -ga itd., gl. Škrabec, JS I 145-50; Vondrák, Fris. pam. 28 sl., ne da bi z Meilletom, Études 316 mislili na disimilacijo $d-t>\emptyset$-t, ki pa je tudi možna, prim. zilj. kadiwo §106." An der zit. Stelle wird die Erhaltung der Gruppe $t l-d l$ in der Gailtalermundart behandelt und kommentiert S. 196: "Prvotno $t l-d l$ je prešlo v $l$ le v tistem obsegu kot v češčini, t.j. pri težko izgovorljivi kumulaciji konzonantov, prim. Gebauer, HM. I. 410: griwo, kầuc, šoun, šwà̀. Najbrž po disimilaciji je drugi $d$ onemel v kadíwo, vendar beremo instr. sing. kadidwan in nom. kadidwo v Vrazovem zapisku neke ziljske narodne pesmi”". 
wischen Entwicklung äussert sich Ramovš ibid., S. 198f. (mit der Lit.) und zu der sekundär entstandenen Verbindung $t l-d l$ im Slowenischen ibid., S. 200.5 Ramovš 1936, S. 93 f., stellt eine Art Ausgangsposition bzw. Zusammenfassung später argumentierter linguistischer Data dar. ${ }^{6} \mathrm{Zu}$ den Verhältnissen zwischen dem West- und Südslawischen vgl. auch Ramovš ibid., S. 84 f. ${ }^{7}$

alpskih krajih, ki so bili kasneje germanizirani, na sedanjem slov. Stajerskem in Koroškem, po Reziji, slovenski Beně̌iji in po Goriškem še neasimilirano $t l$ - $d l$; prehod te skupine $\mathrm{v} l$ se je vršil torej že na slovenskih tleh. Edino za govore na Kranjskem nimamo nobenega znaka, ki bi kazal na $t l$-dl. /.../ Verjetno je, da so tudi prvotni kranjski govori imeli še $t l$ - $d l$, da pa se je prehod v $l$ izvršil tu prej kot v zgoraj omenjenem pasu."

5 "Iz tega bi mogli razbrati, da se je asimilacija prvotnega $t l-d l>l$ (v južni slovanščini in tudi v ruščini) izvršila še pred onemitvijo fonetično slabih reduciranih vokalov $b$ in $b$, ki jo moremo staviti $z$ ozirom na brižinske spomenike nekako v X. stoletje. Vendar moramo priznati možnost, da je moglo eksistirati kako (severno) slov. narečje, ki je obdržalo $t l$ - $d l$ še preko onemitve $s$ in $b$, kakor imamo to v splošnem v zapadni slovanščini, $v$ ziljskem narečju in v jeziku briž. spomenikov, ki pa je kasneje vendarle premenilo $t l-d l>l$ ". Dabei wäre es wichtig, wenn man bestimmen könnte, ob rum. mocirlă schon vor dem X. Jh. entlehnt worden war. Zu der behandelten Problematik im Slowenischen vgl. weiter Ramovš 1936, S. 47 f:: "Po običajnem mnenju sta se skupini $t l$ in $d l$ že $\mathrm{v}$ praslovanski dobi $\mathrm{v}$ vsi južnovzhodni psl. dialektični oblasti asimilirali $\mathrm{v}-l$-, zapadna praslovanščina pa je obdržala $t l, d l$; v glavnem je to pravilno, vendar pa zahtevata dva otoka pojasnitve: severnoruski dialekt pri Pskovu in Novgorodu govori $k l, g l$, ki predstavljata le varianto starega $t l, d l$. V slovenščini pa je bilo ozemlje neasimiliranega $t l, d l$ nekoč še mnogo večje; ugotoviti moremo, da sta ves slovenski sever in zapad govorila še dolgo po naselitvi v Alpah neizpremenjeno $t l$ in $d l$. /..Po zožitvi tega severno-zapadnega pasu $\mathrm{z}-d l$ - v obeh smereh (od vzhoda proti zapadu in $\mathrm{z}$ juga proti severu) je danes od njega ostala le še najskrajnejša zapadna obrobna ploskev, na kateri se govori ziljski dialekt, ki ima za psl. $t l, d l$ isti razvoj kot zapadna slovanščina/.../. Relikti pa so tudi še v drugih koroških in zapadnih dialektih ohranjeni: oblika modliti je znana po savinjski dolini in mislinjski dolini, v mežiški dolini in na Kozjaku (nekoð̌ je bila doma tudi na Koroškem, kjer pa jo je izpodrinila tujka žebrati iz nem. *sefern); /.../V brižinskih spomenikih beremo modliti, modlim in tudi že vzedli. Le za Kranjsko nimamo nobene oblike z $-d l$ - sporočene; viri nam za ta pas potekajo itak iz mlajše dobe in domnevati bi smeli, da se je asimilacija $d l>l$ na jugu vršila prej kot na severu in da zato ni iz teh krajev nobene priče za staro skupino."

Vgl. noch ibid., S. 49: "Ozemlje oblike padla je geografsko strjeno in predstavlja severno-zapadno obrobno ploskev s starim, neasimiliranim - $d l$ - in obsežen podalǰ̌ek v južnovzhodni smeri. /../ Tako moremo vsaj domnevati, da se je $t l, d l \mathrm{v}$ prvotni alpski slovanščini govorilo neasimilirano po vsem višinskem alpskem predelu; od vzhoda sem prodirajoča inovacija $l$ za $d l$ pa je zajemala čedalje globlje $v$ ta pas in pustila do danes izven svojega vplivnega radija samo še ozemlje ziljskega dialekta. Vsaj za ta severno-zapadni del alpske slovanščine moramo reči, da je njen pojav $d l>l$ izvršen v Alpah, v dobi do 12 . stoletja, in da je nezavisen od ruskega pojava $d l>l$ in najbrž tudi nezavisen od prvotnega južnoslovanskega $d l>l$ (stara cerkvena slovanščina ima že $-l$-), od katerega pa je bil pozneje vplivan ob vsi svoji južnovzhodni meji. Določiti čas, kdaj se je asimilacija alpskega $d l>l$ izvršila, /.../ ni možno".

6 "Lingvistična dejstva, ki smo jih pravkar razbrali, nam povedo, da sta alpska in panonska slovanščina (današnja deloma ohranjena, deloma preoblikovana reprezentanta sta slovenščina in kajkavščina) izšli iz onega praslovanskega dialektičnega pasu, ki je skupini $t l, d l$ imel neizpremenjeni in je -ojo skrčil v $-Q$; to je bil zapadni psl. pas dialektov, njegov današnji potomec je zapadna slovanščina. S tem ni rečeno, da sta alpska in panonska slovanščina 6. stol. bili zapadnoslovanska dialekta, saj v tem času še ne moremo govoriti o južni, zapadni in vzhodni slovanščini, marveč samo o psl. dialektih, ki so komaj začeli izobraževati take pojave, ki postanejo značilni in s tem prično formirati južno, zapadno in vzhodno slovanščino. Pri tem ni toliko važno, da je alpska in panonska slovanščina obdržala $t l, d l$ kot to, da je poleg $t l, d l$ imela $-Q$. Ta fakt nas sili k zaključku, da je alpsko-panonski dotok Slovencev prišel iz ozemlja zapadne praslovanščine".

"Jezikovno ni bilo razlik med obema, vsaj v dobi 6. stoletja še ne; za razmerje med zapadno in južno 
$\mathrm{Zu}$ der Vereinfachung der Verbindung $* t / d l$ insbesondere in den südslawischen Sprachen noch einige weitere Deutungen. Arumaa 1976, S. 73, meint, dass die zit. Gruppe auch srkr.-dialektisch erhalten blieb. ${ }^{8}$ Dafür habe ich bislang keine weitere Bestätigung gefunden. Vgl. dazu z.B. Belić 1960, S. 143 f. ${ }^{9}$, weiter u.a. Shevelov $1964^{10}$ und noch Meillet 1902, S. $130 .{ }^{11}$

slovanščino vse todogajanje še nima pomena. Dejstvo, da imamov zapadnih slovanskih dialektih še prefiks $v y$-in neasimilirano $t l$, $d l$ (kakor $\mathrm{v} z$ zapadni slovanščini in proti jžsl. $i z, l$ ) niti ne pravi, da so Slovenci segali do Donave in bili sosedje zapadnih Slovanov, niti ne priča za to, da so zapadni Slovani bili naseljeni po Avstrijskem in v Alpah, niti za to, da so alpski Slovani neposredno pred prihodom v Alpe bili sosedje zapadnih Slovanov; vy- imamo sprva povsod, v 9. stoletju še v enem najjužnejših slovanskih govorov (iz solunske okolice), Dudlebe pa srečamo najprej celo v ozemlju vzhodnih Slovanov ob Bugu z $-d l$-, potem v Alpah z -dl-, ki se pa ščasoma asimilira v - $l$ - (Dulieb 1060-70 pri Spitalu na Koroškem; hrv. Dulebzka terre v Zagorju), ker se je medtem vršil jžsl. proces $d l>l$, in dalje na Češkem - kjer se ta proces ni vršil še danes Doudleby."

Vgl. noch ibid., S. 86: "Nekaj pojavov je samo znak splošne konservativnosti severnozapadnih slovenskih dialektov, ki niso ohranili samo $t l, d l$, in $v y$-, ki bi naj bili priča nekdanjega jžsl.-zapsl. sosedstva, marveč še imperfekt (v Reziji), kondicional bê ( $v$ Benečiji, Reziji in v modificirani ziljski obliki bêsəm), nazalne vokale v podjunščini (pa vendar nikomur ne pride na um, da bi zato iskal in upravičeval zvezo s poljščino), obliko brater, določno dobrê < dobroje na Koroškem itd..; vsi ti slov.-dial. pojavi so v zvezi z odnosnimi zap.-slovanskimi, ta zveza pa gre preko praslovanščine."

8 "Im allgemeinen zeigt die Gruppe Dental $+l$ im slavischen Bereich zweierlei Entwicklung: die westslavischen Sprachen haben hier den Dental bewahrt, wogegen die übrigen Slavinen $d l, t l$ zu $l$ vereinfacht haben. Doch lässt sich diese Zweiteilung nicht einwandfrei durchführen, vgl. besonders das Isoglossensystem bei TESNIËRE, RES 13 (1933) $51 \mathrm{ff}$. Die Erhaltung von $d l$ reicht noch etwas über das Tschechische hinaus in den Bereich der nordslovenischen Mundarten." Und weiter,S. 74: "Wie schon oben angedeutet, nehmen das Nordslovenische und die kajkavische Mundart des Serbokroatischen eine Sonderstellung ein, da sie die Gruppe Dental $+l$ in der Regel nicht zu $l$ vereinfacht haben. Hier muss ein genetischer Zusammenhang mit dem Tschechischen vorliegen, was um so auffälliger ist, als die slavischen Ortsnamen in Ungarn, vgl. KNESZA, Studia Slavica 9 (Budapest 1963) $27 \mathrm{ff}$., vorm früheren $d l$ keine Spur mehr zeigen. Das hohe Alter der Vereinfachung zu $l$ bezeugen auch die slavischen Ortsnamen in Griechenland. /.../ Der Schwund der Dentale offenbart sich auch in germanischen Lehnwörtern, so z.B. ar. Gslëbß, aus anord. Gudleifr oder im Stammesnamen ar. Dulěbi pl., ačech. Dudlebi, aus westgerm. Deudolaifs PN, vgl. Dietleip".

9 "Jedna od osnovnih osobina našeg jezika jeste da praslovenske grupe $-d l$ - $\mathrm{i}-t l$ - uprošćava. On se u tom pravcu slaže ne samo sa svima južnoslovenskim jezicima nego i sa celom ruskom grupom; dok zapadnoslovenski jezici čuvaju grupe $-d l$ - i $-t l$-: molitb, moliti : polj. modlić, češ. modliti; r. plël, pleo, plelı st. slov.: č. pletl, p. plotł itd."

10 Vgl. zur Chronologie (zusammenfassend, S. 202): "The clusters $t l, d l$ are preserved in a part of the S1 languages, viz. $\mathrm{P}, \mathrm{US}, \mathrm{Pb}, \mathrm{Cz}$; with some exceptions in $\mathrm{LS}$; $\mathrm{Sk}$ and $\mathrm{Sn}$ are crossed by isoglosses of the phenomenon. /... In particular, this attribution is supported by the fact that $S k$ isoglosses of separate words with $t l, d l$ preserved or simplified into $l$ seem to continue the corresponding isoglosses of $\mathrm{Sn}$. This indicates that the change of $t l, d l$ into $l$ took place before the Proto-Sk tribes were separated from the Proto-Sn by the German and Hung settlers, i.e. before the eighth-ninth centuries, but at or after the time when SI settlements spread to their present territory in the West, i.e. not sooner than the fourth or fifth century A.D.", und weiter, S. 373: "On the basis of the identical distribution of the isoglosses running through $\mathrm{Sk}$ and $\mathrm{Sn}$ it is assumed that this sound change could not have occurred sooner than the fourth-fifth century A.D., when the Slavs appeared in the area, nor later than the eighth-ninth century, when the Germans and the Hungarians broke the ties between the W and S Slavs. /.../Consequently, the change $d l>l$ did not take place before the second half of the sixth century. On the other hand, the FrFr compiled ca 850 A.D. have a simplified form (crilatcem 
Vgl. weiter zur Deutung der Verbindung $t l / d l$ u.a. noch Vaillant 1950, S. 88. ${ }^{12} ; \mathrm{V}$. Oblak 1897, S. 321-328..$^{13}$ und einige weitere Meinungen. ${ }^{14}$ Unter Spezial-Untersuchungen vgl. noch Kronsteiner 1976, S. 217-227.15

'angel', dat pl, not kridl-). This gives approximately the range between $600-850$." Vgl. noch ibid.: "To summarize, the change $t l, d l>l$ must have occurred between $600-850$, most likely between $700-850$. It was unproductive when the weak $\boldsymbol{b}, \boldsymbol{b}$ were lost (early tenth century in SSI)" und S. 374: "The change $t l$, $d l>l$ was a mere assimilation of two dentals $/ . . . /$ Its gradual expansion from one word to another as visible from the variety of isoglosses in Central Sl is typical of sound changes based on environmentally conditioned assimilations. The simplification of $t l, d l$-clusters did not introduce any changes in the SI phonemic system. It was a marginal development, not a requirement of that system. This explains why it was slow in moving to the NW so that it never affected the Carpatho-Alpine Sl dialects. /.../The changes of $t l$, $d l$-clusters did not fit into the traditional division of Sl into E, W and SSI. All three groups were cut by isoglosses of the change, not a surprising fact because of the instability of the SI groups at that time."

11 'Les groupes $t l, d l$ subsistés en slave commun, ainsi que l'attestent les langues slaves occidentales et les dialectes les plus occidentaux du slovène (Oblak, Arch. f. sl. ph., XIX, 321 et suiv.: on lit encore modliti, vzedli (mais crilatcem) dans les monuments de Freising); la réduction à $l$ dans les autres dialectes slaves résulte simplement de la difficulté que présente la prononciation de $t l, d l$, difficulté qui est essentielle." Vgl. dazu u.a. Ramovš 1937, S. 11: "Poleg $d l$ v modliti, modlim, vzedli II 59, 36, 62 imamo že asimilirano $l$ v crilatcem I 4."

12 "Mais les groupes $t l, d l$ se sont altérés dans une partie du domain slave: maintenus dans les langues septentrionales, ils se sont réduits à $l$ dans les langues méridionales et en russe, c'est-à-dire qu'à la fin du slave commun, ils s'étaient dialectalement assimilés en * $l l$ ". Vgl. weiter, S. 89: "Cette réduction de $t l, d l$ à $l$ 'est pas un fait ancien et ne constitue pas une division bien profonde entre les dialectes du slave commun. L'isoglosse partage le slovène en deux zones: l'une du sud et de l'est qui a réduit les groupes, l'autre du nord et de l'ouest qui les conservait; on y trouve encore dans les parlers jedla, modliti. Le vieux slovène de $\mathrm{X}^{\mathrm{e}}-\mathrm{XI}^{\mathrm{e}}$ siècles écrit modliti comme le slavon morave, mais crilatcem 'aux (anges) ailés', de *kridlo 'aile', tch. křidlo, v.sl. krilo".

13 So z.B. S. 322: "Es war demnach in älterer Periode $d l$ im Slovenischen über ein viel grösseres Gebiet verbreitet als heutzutage", und S. 323: "In einem Worte ist auch heute die Verbindung $d l$ im Slovenischen weit über die Grenzen des Gailthalerdialectes hinaus verbreitet. Es ist das Verbum moliti."

14 Z.B. Leskien 1969, S. 50; Trubetzkoy 1925, S. 117-121; Vondrák 1924, S. 369, 466; Miklosich 1879, S. 343 f, 379; Škrabec 1916-1921, S. 217-227.

15 Vgl. z.B. S. 218: "Mit grosser Wahrscheinlichkeit haben Teile Österreichs (das nordöstliche Niederösterreich) zu jenem politischen Gebilde mit slawischsprechender Bevölkerung gehört, das die Historiker 'Grossmähren' nennen und zu jenem (Teile Niederösterreichs, des Burgenlandes und der Steiermark), das sein Zentrum um den Plattensee hatte, während Karanthanien (Kärnten und Teile der Steiermark) überhaupt als vorwiegend 'slawisches Gebiet' galt. Es wäre nun durchaus verständlich, dass in diesen Regionen verschiedene slawische Sprachen/ Mundarten gesprochen wurden. Man rechnet heute manche Gebiete Österreichs der westslawischen, andere der südslawischen Sprachgruppe zu. BEZLAJ /.../ vermutet auch ostslawische Splittergruppen", weiter S.220: "Die bisher von Historikern geäusserten Ansichten über die slawische Besiedlung Österreichs lassen sich etwa so zusammenfassen: jene Slawen nördlich des Alpenhauptkamms sind aus dem Norden zugezogen, somit Westslawen; die Slawen südlich des Alpenhauptkamms waren Balkanslawen, die aus dem Süden längs der Flüsse Save, Drau und Mur in die Alpentäler vordrangen, somit Südslawen. Wir hätten es also auf österreichischem Gebiet mit zwei verschiedenen Slaweneinwanderungen, einer west- und einer südslawischen, zu tun, die nicht genau zur selben Zeit stattgefunden haben mussten, und die wahrscheinlich vielerorts ineinander übergingen", und S. 221: "Ich will versuchen, hier meine in der 'Österreichischen Namenforschung' begonnene Darstellung des $d h$-Gebiets (Beispiel: sedlo/selo) mit Namen zu ergänzen, die ebenfalls die Lautgruppe $d h$ (in Wörtern wie močidlol močilo, jedla/ jela u. ä.) enthalten. Ich bin mir durchaus bewusst, dass es nur ein Anfang ist. 
Von besonderer Bedeutung scheint die Abhandlung von Schuster-Šewc 1964, S. 359-368 zu sein. ${ }^{16}$ Man vgl. auch schon Miklosich 1872, S. 34 (Kapitel "Ertrag der Ortsnamenforschung für die Grammatik"). ${ }^{17}$

Gerade aber die Lautgruppe $d I /$ könnte als vielversprechendes Unterscheidungsmerkmal zwischen dem West- und Südslawischen dienen und uns helfen, den Begriff 'alpenslawisch' zu differenzieren."

Vgl. noch S. 221 f.: "Es soll nicht unerwähnt bleiben, dass die Lautgruppe $d l$ im Nordwesten des heute slowenischen Sprachgebiets, im Gailtal, noch erhalten ist, ebenso wie (sporadisch) im Jauntal, nicht aber im Rosental. RAMOVŠ glaubt, dass um das Jahr 1000 auch der nordöstliche Teil des slowenischen Sprachgebiets, die Steiermark, noch $d l$ hatte, das dann teils durch südöstlichen Einfluss, teils durch eigenständige Entwicklung zu $l$ wurde. /.../ Dennoch zeigt die Karte ziemlich deutlich ein $d l$ - und ein $l$ Gebiet. Das $l$-Gebiet dürfte allem Anschein nach doch alt gewesen sein, und nicht erst durch Innovationen entstanden sein." In der Weiterführung zitiert Kronsteiner Namen mit der Gruppe $d l /$.

16 Vgl. einige seiner Deutungen, so z.B. S. 360: "Die ursl. Silbengrenzverschiebung erfasste das ursl. Sprachgebiet nicht, wie Trubetzkoy annimmt, vom Nordwesten her, sondern sie muss umgekehrt zuerst im Süden und Osten eingesetzt haben, und zwar zu einer Zeit, da dem ursl. phonologischen System Konsonantenverbindungen vom Typ $t l, d l$ noch nicht geläufig waren, deshalb im Ursüdostslawischen *vedlı $>$ *velъ. Diesem Prozess unterlagen jedoch nicht Wörter des Typs *svetblo und *metbla, aruss. sedslo, da ja hier vor dem Schwund der reduzierten Vokale die Silbengrenze weiterhin zwischen Verschlusskonsonant und Liquida verlief und so die Bedingungen für ihre Zurückziehung noch nicht gegeben waren. Das gleiche betraf heutiges anlautendes $d l$ - und $t l$-, da es ja ebenfalls erst sekundär entstanden ist. /.../ Ursprüngliches, auf das Indoeuropäische zurückgehendes anlautendes $t l-, d l$ - kannte das Slawische nicht."

Vgl. weiter S. 362: "Westslawisches $t l, d l$ gehört deshalb in eine Reihe mit südostslawisch svetlo, metla, wo ja die Gruppe $t l$ ebenfalls erst später entstanden ist", S.364: "Interessant ist, dass mit Ausnahme des Polnischen in allen jenen westslaw. und slowen. Dialekten, wo $k l, g l$ für $t l, d l$ belegt ist, auch $l$ für $d l$ vorkommt", und S. 367: "Durch die frühere Zurückziehung der ursl. Silbengrenze im Süden und Osten des ursl. Sprachgebiets entstehen neue, dem Urslav, ungewöhnliche Konsonantenverbindungen [tl, dl]. Sie werden deshalb zu $l$ vereinfacht. Dieser Prozess setzte noch vor der ursl. Liquidametathese, der Aufspaltung der ursl. sonant. Liquiden und dem Abfall der schwachen reduzierten Vokale ein. Wörter vom Typ aksl. světblı adj. 'leuchtend', tslo 'Boden', tbleti 'verderben', dlanь 'Handfläche', dlıgota 'Länge' (dlgota) werden deshalb von dieser Entwicklung vorerst nicht erfasst. Im Westslaw. bleibt der ursprüngliche frühurslaw. positionsbildende Zustand mit unveränderter Silbengrenze länger erhalten, desgleichen im Bereich des Nordruss. und Nordslowen. (periferischer Archaismus). In diesen Gebieten werden die ursl. Liquidaverbindungen deshalb zu dieser Zeit noch nicht vereinfacht bzw. verändert."

Vgl. endlich noch ibid., S. 367 f.: "Die Zurückziehung der ursl. Silbengrenze erfasst auch den Nordwesten des ursl. Sprachgebietes, doch erst zu einer Zeit, da die Konsonantengruppen $d l, t l$ für den Slawen im grossen und ganzen schon aussprechbar geworden waren. Doch wirkte die Tendenz zur Beseitigung der für das Slawische ungewöhnlichen Liquidaverbindungen auch zu dieser Zeit noch im gesamten slawischen Sprachgebiet weiter. Die Dissimilation trat jetzt aber nur noch sporadisch auf, und ihre Resultate waren nicht mehr einheitlich. Neben $-l$, das nur aus der Vereinfachung von $d l$ entstehen kann, erscheint jetzt auch $k l$ und $g l$, vereinzelnd auch $r l$ und $l l$. Am intensivsten wirkt dieser Prozess an der Peripherie des eigentlichen $t l-, d l$ - Gebietes (Slowen., Slowak, Niedersorb. und Nordruss.), er tritt aber auch verschiedentlich im Zentrum des westslaw. Sprachgebietes auf. (Pol.)."

17 "Allgemein nimmt man an, dass das Slovenische die Verbindung $d l$ durch Ausstossung des $d$ vermieden habe. Genauere Betrachtung des Nsl., namentlich in der im Westen des Sprachgebietes gesprochenen Varietät zeigt die Unrichtigkeit dieser Ansicht; denn da findet man jêdel für jêl ; desgleichen das Suffix dlo für lo: kresadlo, motovidlo, šidlo Janež. 17. Dieselbe Verbindung bewahren einigemal die deutschen Formen slavischer Ortsnamen: Matschiedel močile Kärnt.; Jedlonig Steierm., das mit jela, ehedem jedla, zusammenhängt; Zedl, Zedlach, Zedlich in Kärnt. setzen sedlo, jetzt selo, voraus. Das hat Šafar̆ik, Starožitnosti §41, der für die Nationalität der pannonischen Slaven die Form dudlebi (doudlebi) als entscheidend ansieht, übersehen, der auch darin irrt, dass er $d$ als ein Einschiebsel - př́suvka - ansieht, da 
Für die Frage nach der Etymologie von rum. mocirlă im Rahmen der Problematik der *tl/dl-Entsprechungen gibt Ramovš 1936, S. 59 einen gewissen Anhaltspunkt, wenn er schreibt: “ ...[da sta povsod še eksistirala /...] morda v zgodnejši dobi celo $t l$ in $d l$ (rum. mocirlă, če je iz močidlo, bi govorilo za to; Skokova razlaga iz močvara > *močlara, *močarla je prisiljena, sklicevanje na dejstvo, da je - $d l$ - ohranjeno v zapadni slovanščini, pa za južnoslovanske govore 6. stoletja ne pomeni nič /.../; uvaževati je tudi dejstvo, da je ime Dudlebov, ki so jih Obri porazili in razgnali ter s seboj gnali, pri južnih Slovanih izkazano z $-l$, torej se je proces $d l>l$ vršil po 6. stoletju; hrv. priimek Dulibić)." 18

In seiner Rezension mehrer Arbeiten von P. Skok, die Puşcariu 1924 veröffentlichte, vgl. besonders S. 832 f. ${ }^{19} \mathrm{Zu}$ einer ähnlichen Deutung gelangte auch Stieber

ja nicht nur im Suffix dlo, sondern auch sonst nur von einem Ausfalle des $d$ die Rede sein kann. Der eben so weit verbreitete als räthselhafte Name lautet kroat. dulibe, dulebska: vergl. ad tudleipin Grenzregulierung 27 čech. doudleby; doudlebích Teindles; dúdleby und dúdlebci; klruss. dułyby. Vergl. tittleibe Dronke 79. ahd. totleiba Förstem. 107."

18 Vgl. Skok 1922-23, S. 49 f.: "Pour mocirla 'marais, marécage' propose Tiktin o.c. un dérivé slave *močirlo de mokro dont la formation ne saurait être expliqué par les lois slaves. Cella suffit pour rejeter ce *močirlo d'ailleurs tout à fait hypothétique. Le mot roumain s'explique plus aisément par scr. močvara qui, supposant le passage de moč - $i$ sf. parmi le thèmes en $-y$, -ъve, contient le suffixe augmentatif -ara comme ploštara

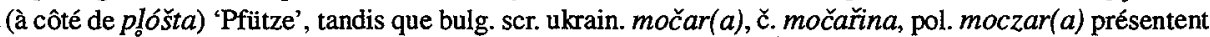
le même suffixe ajouté au thème en $-i$. Les groupes consonantiques slaves avec $v, n$ 'importe si c'est comme le premier ou comme le deuxième élément (excepté $v r$ ), ont subi tous en roumain des déformations ou substitutions plus ou moins considérables, ce qui est bien naturel, puisque le latin n'en a légné aucun au roumain. L'élément labial en a été remplacé quelquefois par $l$, comme en bratbstvo $>$ breaslă, de même que dans le nom de lieu slovène Ponikva > Ponigl en Styrie. Il en était de même de čv dans le mot en question. močvara a dû donner, avec la métathèse des liquides, *močarlă, dont ar, ayant été transformé en $\hat{i r}$ comme en firtat de *fratratu, gîrnată à côté de grenată, granată, après la palatale, s'est changé régulièrement en $i r$."

19 “Explicarea lui mocirlă (p. 490-491) nu mă convinge. Skok pleacă de la o premisă nedovedită că grupa consonantică $r$, fiind neobicinuită în româneşte (dar avem stârv, zarvă, curvă etc.) a lost înlocuită prin $r l$ şi deci serbo-cr. močvara, cu metateză *močarva ar fi dat močarlă; pentru $a>\hat{a}$ citează analogia lui fârtat, unde insă $a>\breve{a}$ (apoi $\hat{a}$ din cauza lui $r$ ) se explică din cauza lipsei de accent. De sigur că nici prototipul slav *močirlo, presupus de Tiktin, nu e admisibil, căci el nu se explică din punct de vedere al derivării slave. Dar Tiktin dăduse mai nainte (supt cuvântul codirlă) o altă explicare: mocirlă = polon. moczydlo, care, cred, ne indică drumul de urmat. Răspândirea geografică a cuvântului pe întreg teritoriul românesc, ne împiedecă a-i căutà originea în limba polonă; dar derivatul *močidlo (pentru sufix, derivând şi numiri locale, v. Vondrák, Vergl. slav. Gramm. I, 439) a putut existà şì la Slavii de sud. Ungurescul mocsila (=mocsola, mocsolya), cu acelasi sens, presupune şì el un *močidlo, devenit *močilo. Prefacerea grupei $d l$ (neexistentă în cuvintele moştenite) în $r l$ se explica uşor foneticeşte şi e cunoscută şi din alte limbi; ea s'a repetat mai târziu în povirlă $=$ povidlă $<$ polon. powidlo, Corlea $=$ Codlea, potlog $>*^{*}$ podlog $>$ (Braşov) porlog, ceatlău > ceadlău > cearlău (Viciu, Gl.), horlangăr < germ. Handlanger. Poate ca şi românescul cârlobat "încovoiat, adus, strâmb" să stea în legătură cu polon. kadtub '(vas făcut dintr'un) butuc' (Berneker, S1. Wb. 467). Pentru dârlog (cu varianta dălog!) ne-am puteà gândi la sinonimul bulgăresc udilo (= vodilo din vodja 'lenke' şi suf. -ilo): forma mai veche *udidlo àr fi dat *udirlă şi, cu sufixul -og, *udirlog, care a putut fi analizat în $\tilde{u}(=u n)$ dirlog, mai ales fiindcă cuvântul e întrebuințat cu deosebire la plural (cf. frâne). Trecerea lui $i$ în $\hat{a}$ s'ar explicà (din cauza lui $r l$ ?) ca în codârlă alături de codirlă, care şi el ar puteà fi un derivat din coadă ca sufixul slav -ilo, pe când se rosteà încă -idlo ${ }^{1}$. Varianta dălog ar reprezentà forma mai nouă slavă udilo." Vgl. weiter S. 833, Anm. 1: "Cf. şi şopârlă, care se aseamănă cu alb. šapi dar şì cu alb. 
1969, S. $81 \mathrm{f}$. bei der von ihm behandelten Verbindung $t / / d l$. Er stellt fest, dass in der griechisch-slawischen Toponomastik, welche andernfalls grosse phonetische Archaismen aufweist, die Gruppe - $d l$ - nirgends erhalten ist. Als Beispiel des Reflexes - $l$ - führt

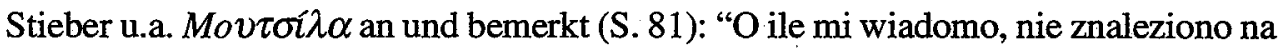
terenie Grecji, żadnego toponimu słowiańskiego pochodzenia, z zachowaną grupą all." Weiter nennt er, dass auch in den slawischen Toponyma in Rumänien die Verbindungen $-t / / d l$ - nicht vorkommen, er stellt jedoch folgendes fest (ibid., 81 f.): "Tylko v

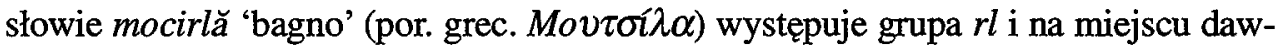
niejszej $d l$. Mielibyśmy 1 tu p̌rzykład likwidacji grupy $d l$, tylko w inny sposób, przez zmianę jej na $r l . / .$. / Uwzględniając wyżej podane fakty z Grecji, można z pewnym prawdopodobieństwem przyjąć, że grupy $t l, d l$ zanikły w dialektach wschodniej części Słowian jeszcze w okresie przed wielką migracją Słowian na południe. Likwidację tę przeprowadzono na dwa sposoby: albo usuwając w grupach $t l d l$ spółgłoski zwarte, albo też zmieniając. je na zwarte innego szeregu $(k, g)$ albo też wreszcie wyjątkowo na $r$. Stąd brak grup $t l d l$ w toponomastyce grecko-słowiańskiej i rumuńsko-słowiańskiej oraz w zapożyczeniach słowiańskich w językach greckim i rumuńskim." Ähnlich äussert sich auch Stieber 1965, S. 304-308. Man vergleiche S. 306f. und speziell die Formulierung S. 307, die lautet: "Cały ten dość obfity materiał wskazuje, że Słowianie, którzy w większych masach wtargnęli do Grecji gdzieś około 600 r.n.e., mieli już w swoich dialektach stale $l<d l$. Na prasł. $t l$ niestety brak przykładów w greckiej toponomastyce. Formy z $l<d l$ występują też w toponomastyce słowiańskiej na Węgrzech, co dobrze nawiązuje do obszaru środkowosłowiackiego z częstym typem sillo".

Der von Ramovš (zwar etwas zurückhaltendere) Vorschlag der etymologischen Deutung von rum. mocirlă lässt gewisse Alternativmöglichkeiten offen. Wegen der möglichen slawischen Entsprechungen müsste man einerseits die Möglichkeit einer slawischen Ausgangsform mit - $r-/-r l$ - annehmen..$^{20}$ Andererseits müsste man, wie be-

džaperdone, cu acelaşi sens. Pentru prefacerea lui $d$ în $r$ înainte de $n$ avem în româneşte exemple ca: logornă $=\operatorname{logodnă} / . . . /$ Prefacerea lui $d l$ în $r l$ e obicinuità în dialectul săsesc din Ardeal: šerl $=$ Schädel, $k n e r l=$ Knödel $/ . . .{ }^{\prime \prime}$.

Puşcariu rechnet zwar mit einer Entwicklung $d l>r l$, dennoch, wie es scheint, in einer späteren Phase, wenn "povirlă = povidlă < polon. powidlo /...P" wörtlich zu verstehen ist, wie auch die deutschen Entlehnungen auf einen späteren, möglicherweise produktiven Prozess hinweisen mögen. In diesem Fall wäre das Phänomen für die Erläuterung der südslawischen Vereinfachung bzw. Erhaltung der Gruppe *tl/dl ohne Belang.

20 Man vergleiche z.B.: Miklosich 1886, S. 199 f.: s. mok-: S. 200: nsl. močêr, močvêr, močvir, močvar "sumpf". močilo "lache" /.../ b. močorliv "sumpfig" /.../, rm. močirle sumpf. magy. pamacs, pemecs, pamacsol vb. mocsár. močsola. /.../ alb. močal'.

Vgl. weiter Raevskij et al. 1978, S. 267, wo močirlë als eine Entlehnung aus dem Südslawischen dargestellt wird und dabei folgende slawischen Formen angeführt werden: bulg. močurlak, močir, močur; srkr. mồčar. Mladenov 1941, S. 305, zitiert s. močs u.a. močarb, močurb, močurenъ, močurlákъ, močurlivъ, močurlivost.

Andrejčin et al. 1973, S. 472, führen folgende bulgarischen Formen an: močur m. "blatisto, vlažno mjasto, pokrito s trava; tresavišče, mlaka"; močurišče n. "močurlivo mesto", adj. močurliv. 
sonders aus der rumänischen etymologischen Literatur ersichtlich ist, auch mit einer internen, rumänischen Suffigierung rechnen. Man vgl. dazu z.B. Conevъ 1934, S. 1 ff., Kapitel "Ezikovi vzaimnosti meždu błlgari i rumъni". Er führt u.a. auf S. 41 folgende Belege an: mocirlă blato, močur, mociurlos - močurlivo und morciolesc, morcioleata.

Wegen der reellen Möglichkeit einer bulg. Ausgangsform für das rum. mocirlă versuchte ich anhand des bei Conevъ behandelten Materials folgendes zu überprüfen: 1) ob andere Fälle mit einem Wechsel des $-i$ - und $-u$-Vokals bestehen und 2) aus welcher Ausgangsform andere rumänische Bildungen auf -lă, die in dem Material vorkommen, (wahrscheinlich) entstanden sind bzw. umgekehrt, wie die Entsprechung vom bulg. - lo im Rumänischen reflektiert wird. Auf diese Weise versuchte ich Indizien zu finden, ob in diesem Material weitere Fälle für die angenommene Entwicklung slaw. *-dlo (bulg. als -lo belegt) > rum. -rlă vorliegen.

Bei der [von Ramovš, vgl. auch Stieber] (versuchsweise) vorgeschlagenen Etymologie muss man nämlich sehr genau vorgehen, da sie (anscheinend) den isolierten Fall einer Beibehaltung der Gruppe $-d l$ - in dem Südslawischen voraussetzt (Slowenisch-dialektisch ausgenommen), weil keine weiteren Fälle in der rumänischen Toponomastik registriert worden sind und weil auch in den griechischen Entlehnungen aus dem Slawischen und in der Toponomastik auf griechischem Gebiete keine Relikte dieser Art vorkommen. Bei der erwähnten Wortsippe stösst man andererseits im Slawischen selbst auf verschiedene Bildungen auf- $r$ - bzw. auch $-r l$-. Auch die rum. Parallelbildungen mit - $r$, -rița stellen, wie es scheint, die Erklärung des $-r l$ - <-dl-in Frage.

Zu dem 1) evtl. Wechsel zwischen $-i$ - und - $u$ - bzw. zur Schwankung des Vokalismus könnte man vielleicht als Parallele die bei Conevъ ibid., S. 40 und 57 angeführten Bildungen wie mămă, mămuța, mămuşoară und barborniţa - babura; maştéhă, maştíhă - maščexa vergleichen. Für eine zuverlässige Lösung sowohl der Frage 1) als auch 2) müsste man die Verhältnisse bzw. Möglichkeiten der rumänischen Wortbildung genau untersuchen. $\mathrm{Zu} 2$ ) könnte man vielleicht noch folgende Belege bei Conevъ, o.c. anführen: z.B. S. 60: mănzală - mazalo; sucală - sukalo; S. 61: steclă, sticlă - stъklo; feştilă - svěštilo; (ev. S. 61: sperlă cendre chaude D - spъrl-; sperlescispъrljamъ soščo dvojno značenie: opъrljamъ i poběgamъ); S. 63: cirăpeală cerpalo cirěpъ; (ev. S. 64: zagărlă cedilka vblnena Lit.); S. 64: sădilă, osedilă D - cědilo (za sirene) usw.; (? S. 78: tîrlă, tărlă - ţrlo; tîrlesc nastanjavanъ (ovce) na tъrlo; tîrlas ovčarß otъ ţrlo).

Donevъ 1943, S. 158, zitiert bulg. močors, m., -urъ m. "Sumpf, Morast"; -orlivъ "sumpfig, morastig"; -urlakъ m. "Sumpfboden, Morastboden".

Vgl. noch Berneker 1913/14 II, S. 69 f., der s. mokrъ; močo, močiti u. a. anführt: ukr. močăr(a) "Sumpf", bulg. móčor, močârr, móčur "Sumpf, Moor" und noch z.B.: srkr. mòčalina "Lache", mồcar "Nässe vom Regen"; čech. močă̌ina, močall "Morast, Sumpf"; poin. moczar m., moczaraf. "Sumpf" und ibid.: "Aus dem Slav. rum. mocirlă "Schlamm, Pfütze"; magy. pamacs, pemecs "Pinsel"; pamacsolni "anstreichen";

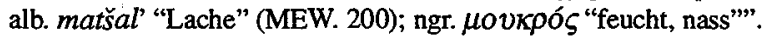


Wie schon erwähnt, besteht auch die Möglichkeit einer internrumänischen Erklärung des Suffixes -irlă. ${ }^{21}$ Vgl. weiter Cihac 1978, S. 200. ${ }^{22}$

Auch die angeführten Toponyma können auf verschiedene Wortbildungsprozesse hinweisen. So könnte man vielleicht z.B. Mocirliu mit dem Adj. bulg. močurliv "sumpfig" zusammenbringen. ${ }^{23}$ Vgl. noch Papahagi 1963, S. 70724; Tiktin 1911, II, S. $1002^{25}$, ibid. mocirlo's "pfützig, morastig, schlammig"26. Vgl. auch schon Miklosich 1861, S. 3027; Miklosich 1872, Kapitel "Die den slavischen Ortsnamen zu Grunde liegenden Vorstellungen", S. $11 .{ }^{28}$ und endlich Miklosich 1874, S. 61 f. s. močarß ${ }^{29}$ und ibid., S. 62 s. močilo. ${ }^{30}$

Zum Problem der slawischen Entlehnungen im Rumänischen vgl. u.a. den umfangreichen Abschnitt "Südslavisches und Rumänisches" bei Popović 1960, S. 199209, 116-121 und zusammenfassend auf dem gegenwärtigen Stand der Forschung

21 Vgl. dazu noch A. Cioranescu, Diccionario Etimológico Rumano I. Biblioteca Filológica. Universidad de La Laguna. 1958-1966, S. 534, No. 5378:" mọceră (-re), s.f. - (Maram.) Marisma, cenagal. Rut. močar /.../ del esl. mocrŭ 'mojado'.- Der moceriță (var. mociorițä), s.f. (pantano), del bg. močor; mocirlă, s.f. (pantano, marisma; basura; medio corrompido), mr. mucirlă, con el suf. expresivo -irlă, cf. ciocîrlă (Miklosich, Slaw. Elem., 30; Miklosich, Lexicon 381; Cihac, II 200; Berneker, II, 70; Conev 40), cf. pol. moczyła, hg. mocsolya; bg.sb.cr. mocar; mocirlos (var. Maram. mociros), adj. (pantanoso); morşilă, s.f. (Banato, pantano). Cf. mocrotă.

Vgl. dazu S. 187, No. 1960: *ciocirlă.. "El suf. es seguramente expresivo, cf. cocîrlă, codîrlă, modîrlan, şopîrlă, țopîrlan)", S. 215 s. coçîrla (-le) : "Formación expresiva, der. de coc 'objeto redondo' como *ciocîrlă de cioc, o codîrla de coadă, scăfîrlie de scafă /.../el suf. -îrlă indica una fuente expresiva."

"Mocírlă, s., mare, limon, fange; -mocirlós, a., fangeux, limoneux; - mocirlesc, i, vb., couvrir de boue, salir; - moínă (pour močină) /.../ - móişte (pour móčiştê) /.../. - vsl. moča /.../, mokrŭ, /.../, polj. moczyła, moczydło, moczadło; moczara, /../, cr. serb. močar, močina; /..l magy. mocsár, macsár "mare"; mocsáras marécageux, mocsolo, mocsolya mare pour rouisage du chanvre /.../ Mocra, Moceştı, Mocilă, Mocirliu, /.../ noms de localités; v. Mikl. App. 355."

Vgl. o. Anm. 20, s. Mladenov 1941, Donevъ 1943, Andrejčin et al. 1973.

s. mučeára ${ }^{1}$, pl. mučérĭ "mocirla", "flague d'eau, mare; limon, fange, boue" zitiert er auch mučiór, mučirlă und vergleicht u.a. auf der slawischen Seite slowen. močer, bg. močurŭ.

moci'rlă, pl. -le "mit schlammigem Wasser gefüllte Stelle: Pfütze, Morast". "Et. Slav. *močirlo, zu mokrŭ 'nass', vgl. nslov. močilo."

Vgl. auch ibid. mociori'ță, pl. -țe “Sumpf” (...) "Et. Vgl. bulg. močor, nslov. moč(v)êr, ruth. czech. močar etc., zu ksl. mokrŭ "nass", also verwandt mit moci'rlă."

močirb : nsl. močir. - močirls f. coenum; močirlesc vb. inquino.

"Die technischen Verwendungsarten des Wassers haben ihre besonderen, in Ortsnamen nicht selten vorkommenden Namen: močilo Flachsröste, rybbnikъ Fischteich".

29 močarz: "nsl. močvar palus, in ON. durch 'Moos' übersetzt. serb. močar udor. pol. moczara. nsl. močvirje Krain. močirje "Mooswald, Mossern" Kärnt. klruss. močary Gal. vergl. močerady Gal. cech. močár Slovak. močárany Slovak. vergl. močerady B."

30 "serb. močilo Flachsröste. čech. močidlo. pol. moczydło. nsl. močile Krain. močidle Matschiedel Kärnt. močula Motschula Kärnt. močilno Krain. močilnik Bach Valv. kroat. močilo Gr. močila Gr. močile $\mathrm{Kr}$. serb. močila Bach Herc. čch. močidlo B. močidlce B. močidly B. močidlice B. močidlky B. močidlník B. močidlany Slovak. pol. moczydło Gal. moczydlica Motschelniz Court. 26. moczydlnice ibid." Vgl. auch o. Anm. 20, Miklosich 1886. 
besonders Solta 1980, so u.a. das Kapitel "Die rumänischen Lehnbeziehungen" ibid. S. 85 ff. und dabei vor allem "Rumänisch-slavische Lehnbeziehungen" S. 85-101"1; zu derselben Problematik noch Stölting 1970, so besonders das Kapitel "Linguistischer Kontakt auf dem Balkan" (S. 3-37). ${ }^{32}$

31 Vgl. z.B. S. 87: "Es gibt etwa 70-80 slavische Lehnwörter, die in allen rumän. Dialekten wiederkehren und die durch besondere lautliche Altertïmlichkeiten ausgezeichnet sind, wie z.B. sŭtă "hundert" aus slav. sbto beweist." Vgl. weiter ibid.: "Die Antwort kann nur lauten, dass sich das Rumänentum zu beiden Seiten der Donau entwickelt hat /.../ und dass vom 10. Jh. an die Kontakte zwischen den Aromunen und den übrigen Rumänen nicht mehr gegeben waren, weshalb die späteren, unverhältnismässig zahlreicheren Lehnwörter nicht mehr gemeinrumän. sind. Diese älteren Lehnwörter sind nach STÖLTING als Adstratverhältnis zu Beurteilen."

Weiter vgl. S. 88: "Die slav. Elemente des Dakorumän., die rein numerisch betrachtet das lat. Erbgut bei weitem überwiegen, sollen nach STÖLTING das Ergebnis eines bulgar. Substrates sein, das sich seit dem 10. Jh. nördlich der Donau bildete und zu einem ausgeprägten slav.-rumän. Bilinguismus führte, mit einer extensiven Aneignung des slav. Wortgutes seitens der Rumänen." Es folgt eine verhältnismässig umfangreiche Darstellung der entlehnten Lexik nach Sachgruppen/Bedeutungsgruppen, wobei mocirlă nicht erwähnt wird.

Vgl. auch von dem methodologischen Standpunkt aus interessanten Feststellungen S.90: "Sicher in den Bereich einer politisch-kulturellen Suprematie gehören die sog. Slavonismen, die nichts über die engeren Beziehungen von Volk zu Volk aussagen /.../. Darunter fallen die kirchlichen Ausdrücke wie molitvă "Gebet", und S. 92 f. s. "Herkunft der Slavismen": "Wenn oben /.../ im Anschluss an die Ansichten von STÖLTING /.../ nur von den Bulgaren die Rede war, so muss noch eines anderen Problems gedacht werden. Ruthen. (d.h. ukrain.) Einfluss konnte bei dem Worte omăt für "Schnee" /.../ angenommen werden."

Zum Problem des "Dakoslavischen" vgl. ibid., S. 92 f. Für das Problem der Zuordnung rumänischer Entlehnungen aus dem Slawischen vgl. besonders ibid., S. 97: "Es ist also kein Zweifel daran möglich, dass sowohl die meisten Wörter wie auch die meisten Ortsnamen slav. Herkunft im Rumän. auf bulgar. Sprecher zurückgehen. Ortsnamen mit serbokroat. Eigenheiten finden sich nur im Westen des rumän. Territoriums (Banat, West-Oltenien, Süd-Siebenbürger), wobei manchmal eine bulgar. Überschichtung erfolgt sein kann."

32 Vgl. in diesem Zusammenhang ibid., S. 9: "Die Mitgliedsprachen des balkanischen Sprachbundes gehören unterschiedlichen (genetischen) Sprachfamilien an: Slavisch (Bulg., Mak., z.T. Serbokroatisch), Romanisch (Dakorumänisch, Arumunisch, Meglenorumänisch, Istrorumänisch), Neugriechisch und Albanisch. Sie zeigen neben vielen lexikalischen und phraseologischen Übereinstimmungen in ibrem grammatischen Aufbau eine grosse Anzahl von Isogrammatismen, die als wechselseitige Entlehnungen zu erkennen sind. Die Voraussetzungen für den zwischen Ihnen aufgetretenen Kontakt sind historische Ereignisse und das daraus resultierende enge räumliche Nebeneinander der Teilnehmer dieser verschiedenen Sprachen. Je enger der geographische Raum des Sprachbundes gefasst wird, um so dichter ist das Netz der Isogrammatismen und umso intensiver der Sprachbund".

Zur zeitlichen Periodisierung der rumän. Entlehnungen aus dem Slawischen vgl. z.B. S. 20: "Die bulg. Elemente im Rum gehören zwei verschiedenen Perioden an, einer frühen von ca. 6.-10. Jhd. und einer späten von ca. 10. Jhd. an abwärts. Die bulg. Lexeme aus der ersten Periode, die durch die Altertümlichkeit des zugrunde liegenden siav. Lautstandes (rum. sută < şto) und durch das Vorhandensein in allen rum. Dialekten (Dakorumänisch, Arumunisch, Meglenorumänisch, Istrorumänisch), d.h. im Frührum. von seiner Aufteilung, oft mit parallelen Veränderungen (vrteti > DR a învîrtì, AR anvîrtésc, MR anvărtés), zu erkennen sind, betragen 70-80 an der Zahl./.../ Da in der Zeit bis zum 10. Jhd. in den Kontaktgebieten das Rum. zur Substratbildung im Slav. tendierte, nicht umgekehrt, und da die heutigen grossen rum. Dialekte auf die Mundarten der möglichst isoliert lebenden und deshalb nicht assimilierten Hirtennomaden zurückgehen, sind die frühen Slavismen im Gesamtrumänischen vorwiegend als Lehnwörter, als Produkte eines Adstratverhältnisses zu betrachten. Dagegen entspringen die slav. Elemente, die im DR ungefähr zwei Fünftel des Wortschatzes slavisch werden liessen /.../, dem sich seit dem 10. Jhd. nördlich der Donau 
Zusammenfassend kann man bezüglich der Etymologie von rum. mocirlă folgendes feststellen: 1) Die Entlehnung aus südslawischem *močidlo ist nicht widerlegbar, sie setzt jedoch eine sehr frühe Entlehnung aus einer Zeit voraus, als die Verbindung *tl/dl noch auf dem ganzen südslawischen Gebiet erhalten war. Beide Voraussetzungen sind (meines Erachtens) nicht zu beweisen. Die andere Möglichkeit wäre, dass es sich um eine Entlehnung aus einer nicht-südslawischen Sprache handelt (z.B. Ukrainisch, Polnisch). Um eine präzise Antwort auf alle drei Möglichkeiten geben zu können, müsste man über exakte Data zu den geographischen und chronologischen Belegen des rumänischen Wortes verfügen, was ich aus der vorhandenen Literatur nicht eruieren konnte. 2) Die Entlehnung aus einer südslawischen Form auf - $r$ - bzw. auch -rl-scheint möglich. 3) Ebenso möglich scheint die internrumänische Deutung mit dem rumänischen Suffix -irlă. Die Etymologie von rum. mocirlă bleibt also in diesem Rahmen offenbar vorerst unentschieden. Die vorgelegte Analyse bzw. die Erläuterung der etymologischen Vorschläge möchte auf Vagheiten bzw. auf das Erfordernis zur Miteinbeziehung möglichst vieler zusätzlicher sprachhistorischer Teilprobleme (morphonologischer, wortbildungsbezogener, kulturhistorischer usw.) aufmerksam machen.

\section{Verzeichnis der angeführten Literatur:}

Andrejčin et al. 1973: Andrejčin-Georgiev-Ilčev-Kostov-Lekov-Stojkov-Todorov, Bъlgarskij ţlkoven rečnik. ${ }^{3}$ Sofija 1973

Arumaa, P. 1976: Urslavische Grammatik. Einführung in das vergleichende Studium der slavischen Sprachen II. Band: Konsonantismus. Heidelberg 1976

Belic, A. 1960: Osnovi istorije srpsko-hrvatskog jezika I. Fonetika. Univerzitetska predavanja. Beograd 1960

Berneker, E. 1913/14: Slavisches etymologisches Wörterbuch. 1: A-L, 1913; M-morb. Heidelberg $1914 ;{ }^{2} 1924$

Cihac de, A. 1978: Dictionnaire d'étymologie daco-romane. ${ }^{2}$ Biblio-Verlag. Osnabrück 1978. Vol. II ( $\left.{ }^{1} 1879\right),{ }^{2} 1978$. Éléments Slaves.

Cioranescu, A. 1958-1966, Diccionario Etimológico Rumano I, Biblioteca Filológica. Universidad de La Laguna. 1958-1966

Conevъ, B. 1934: Istorija na bъlgarski ezik. Tom 2. A. Obšta čast. B. Specialni časti. Posmbrtno izdanie. Sofija 1934.

Donevъ, St. 1953: Bъlgarsko-němski rečnikъ. Sofija 1943

Leskien, A. 1969: Handbuch der altbulgarischen Sprache. ${ }^{9}$ Heidelberg 1969

bildenden bulg. Substrat. Für die Beurteilung der Stärke des slav. Einflusses auf das Rum. in der Zeit bis zum 10. Jhd. können sie nicht herangezogen werden." 
Kronsteiner, O. 1976: Die Bedeutung der Lautgruppe $d l / t l$ für die sprachliche Klassifizierung des Alpenslawischen. Opuscula slavica et linguistica. Festschrift für Issatschenko. Klagenfurt 1976.

Miklosich, F. 1861: Die slavischen Elemente im Rumunischen. Wien 1861

Miklosich, F. 1872: Die slavischen Ortsnamen aus Appelativen I. Wien 1872

Miklosich, F. 1874: Die slavischen Ortsnamen aus Appelativen II. Wien 1874

Miklosich, F. 1879: Vergleichende Grammatik der slavischen Sprachen. Erster Band. Lautlehre./ Vergleichende Lautlehre der slavischen Sprachen. ${ }^{2}$ Wien 1879

Miklosich, F. 1886: Etymologisches Wörterbuch der slavischen Sprachen. Wien 1886

Meillet, A. 1905: Études sur l'étymologie et le vocabulaire du vieux slave II. Paris 1905

Mladenov, S. 1941: Etimologičeski i pravopisen rečnik na bろlgarskija knižoven ezik. Sofija 1941

Oblak, V. 1897: Kleine grammatische Beiträge. 1. Slovenisches $d l$ und südslavisches vy. AfslPh 19, Berlin 1897, S. 321-328

Papahagi, T. 1963: Dicționarul dialectului aromîn, general şi etimologic. Bucureşti 1963

Popović, I. 1960: Geschichte der serbokroatischen Sprache. Wiesbaden 1960

Puşcariu, S. 1924: Dacoromania III (1922-23), Cluj 1924, S. 829-839

Puşcariu, S.- Kuen, H. 1943: Die rumänische Sprache. Leipzig 1943

Raevskij et al. 1978: N. Raevskij, M. Gabinskij (Red.), Scurt dicționar etimologic al limbii moldovenȩsti. Chişinău 1978

Ramovš, F. 1924: Historična gramatika slovenskega jezika II. Konzonantizem. Ljubljana 1924

Ramovš, F. 1936: Kratka zgodovina slovenskega jezika I. Ljubljana 1936

Schuster-Šewc, H. 1964: Noch einmal zur Behandlung der Liquidaverbindungen $t l, d l$ in den slavischen Sprachen. Slavia 33, 1964, S. 359-368

Shevelov, G.Y. 1964: A Prehistory of Slavic. The historical Phonology of Common Slavic. Heidelberg 1964

Skok, P. 1922-23: Des rapports linguistiques slavo-roumains. Slavia I, S. 485-494

Solta, G. R.: Einführung in die Balkanlinguistik mit besonderer Berücksichtigung des Substrats und des Balkanlateinischen. Darmstadt 1980

Stölting, W. 1970: Beiträge zur Geschichte des Artikels im Bulgarischen. München 1970

Stieber, Z. 1965: W sprawie pierwotnego podziału dialektalnego języka prasłowiańskiego. Symbolae Linguisticae in Honorem Georgii Kuryłowicz. Wrocław-Warszawa-Kraków 1965, S. 304-308

Stieber, Z. 1969: Zarys gramatyki porównauczej języków słowiańskich. Fonologia. Warszawa 1969 
Škrabec, P. S. 1916-21: Jezikoslovni spisi I-II. Ljubljana 1916-1921

Tiktin, H. 1911: Dictionar Român-German II. Bukarest 1911

Tiktin, H. 1903-25: Rumänisch-deutsches Wörterbuch I-III. Bucureşti 1903-1925

Trubetzkoy, N.S.: Die Behandlung der Lautverbindungen $t l, d l$ in den slavischen Sprachen. ZfsiPh 2, 1925, S. 117-121

Vaillant, A. 1950: Grammaire comparée des langues slaves I: Phonétique. Paris 1950

Vondrák, W. 1924: Vergleichende slavische Grammatik I: Lautlehre und Stammbildungslehre. ${ }^{2} 1924\left({ }^{1} 1906\right.$ Göttingen)

\author{
Povzetek \\ KRITIČNI ORIS LITERATURE V (JUŽNOSLOVANSKEM) ZASTOPSTVU SKUPINE *tl/dl \\ S POSEBNIM OZIROM NA RUM. mocirlă
}

\begin{abstract}
Etimološka razlaga rum. mocirlă "Pfütze, Morast" < slovan. *močidlo je problematǐ̌na, ker predpostavlja, kot je videti, izoliran primer ohranjene skupine *tl/dl na južnoslovanskem področju (z izjemo sloven.dial. zastopstva). $Z$ ozirom na slovan. ustreznice se zdi verjetna možnost, da je mogoče izhajati iz že slovan. izhodiščne oblike na $-r-/-r l$-. Mogoče je tudi, da gre za tvorbo z rum. (ekspresivnim) sufiksom -irlă ali celo za prekrivanje več možnih izhodišč. Dokončna rešitev ostaja, kot se zdi, odprta.
\end{abstract}

